\title{
Evaluation for Efficient Hairy Root Production Assessed by GFP- gene Expression in Tomato Cultivars Inoculated with Agrobacterium rhizogenes MAFF07-20001
}

\author{
Takeshi FUKUMOTO ${ }^{1}$, Teruo NONOMURA ${ }^{1}$, Yoshinori MATSUDA ${ }^{1}$, Shin-ichirou KOMAKI ${ }^{1}$, \\ Nobuyuki MORIURA ${ }^{1}$, Koji KAKUTANI ${ }^{2}$, Akiyoshi SAWABE ${ }^{3}$ and Hideyoshi TOYODA ${ }^{1 *}$ \\ ${ }^{L}$ Laboratory of Plant Pathology and Biotechnology, Faculty of Agriculture, Kinki University, \\ 3327-204 Nakamachi, Nara 631-8505, Japan \\ ${ }^{2}$ Phermaceutical Research and Technology Institute, Kinki University, \\ 3-4-1 Kowakae, Higashi-osaka 577-8501, Japan \\ ${ }^{3}$ Laboratory of Environmental Biology and Chemistry, Faculty of Agriculture, Kinki University, \\ 3327-204 Nakamachi, Nara 631-8505, Japan \\ *Corresponding author E-mail address: toyoda@nara.kindai.ac.jp
}

Received 28 February 2003; accepted 28 April 2003

\begin{abstract}
When leaf segments of a tomato cultivar 'Ponderosa' were inoculated with Agrobacterium rhizogenes MAFF07-20001 carrying the binary vectors $\mathrm{pRi}$ and $\mathrm{pB}[121 / \mathrm{sGFP}$, adventitious roots were developed from calli formed at the edges of the segments. Primordial roots were obtained with green fluorescence under blue light and elongated vigorously on hormone-free medium without loss of the green fluorescence. They were easily distinguishable from the non-fluorescing roots on the same segments. Successful integration of the SGFP and rol C genes into the chromosome of tomato roots was confirmed by polymerase chain reaction and Southern hybridization. The present method enables us to evaluate the hairy root formation without subculture, isolation and DNA analysis. All commercial cultivars available in Japan (24 cultivars) and 14 breeding lines of tomato were tested by this method. All but two breeding lines produced the hairy roots. Thus, the present method is useful for hairy root production in tomato.
\end{abstract}

Key words: Agrobacterium rhizogenes, GFP, hairy roots, tomato cultivars.

\section{Abbreviations}

GFP, green fluorescent protein; PCR, polymerase chain reaction.

An Agrobacterium-mediated gene delivery is a commonly available technique for genetically transforming higher plants. On account of easy selection of hairy roots, we have used Agrobacterium rhizogenes carrying $\mathrm{Ri}$-plasmid for transformation of melon (Toyoda et al., 1991; Matsuda et al., 1997), tobacco (Matsuda et al, 2001a) and strawberry (Toyoda et al., 1993). In melon, Matsuda et al. (2000) selected hairy root clones that produced fruity, aromatic flavor at higher level than in fresh melon fruits, and Sawabe et al. $(2002,2003)$ pointed out the possible use of these hairy roots as biological material to produce useful compounds. This method has been also applied to tomato cultivars to obtain useful hairy root clones, but it is not always effective in distinction from non-transformed ad- ventitious roots frequently produced in non-infected, detached tomato leaves. Moreover, the efficiency of hairy root formation varied among the cultivars used. To solve these problems, it is of practical importance to clarify the response of major tomato (Lycopersicon esculentum Mill) cultivars against the strains of $A$. rhizogenes for establishing a method for effectively selecting true hairy roots. From this point of view, we attempted to use the $A$. rhizogenes strain containing binary vectors ( $\mathrm{Ri}-$ plasmid and pBI121/sGFP) for inoculation of commercial tomato cultivars. The present paper describes the successful formation of GFP-expressing hairy roots, which enable us to easily select fluorescing hairy roots and to evaluate the efficiency of transformation of tomato cultivars by the strains of A. rhizogenes.

The strain MAFF07-20001 of A. rhizogenes (Toyoda et al., 1991) was used in the present study MAFF07-20001 was transformed with the plasmid vector $\mathrm{pBI} 121 / \mathrm{sGFP}$, which was constructed by 
replacing the GUS gene of the plasmid vector pBI121 (Clontech, CA, USA) with the synthetic green fluorescent protein gene (SGFP(S65T)) (Chiu et al., 1996). The sGFP gene was provided by Professor Dr. Y. Niwa, University of Shizuoka, Shizuoka, Japan. The integration of the plasmid into bacterial cells was conducted by electroporation according to the method previously described (Tanaka et al., 1993). Transformed bacteria were screened in the presence of $25 \mathrm{mg} \mathrm{l}^{-1}$ of kanamycin, pre-cultured overnight and suspended in $10 \mathrm{mM}$ $\mathrm{MgSO}_{4}$ to give final density of $10^{8}$ cells ml-1 as an inoculum.

Commercial cultivars and our breeding lines of

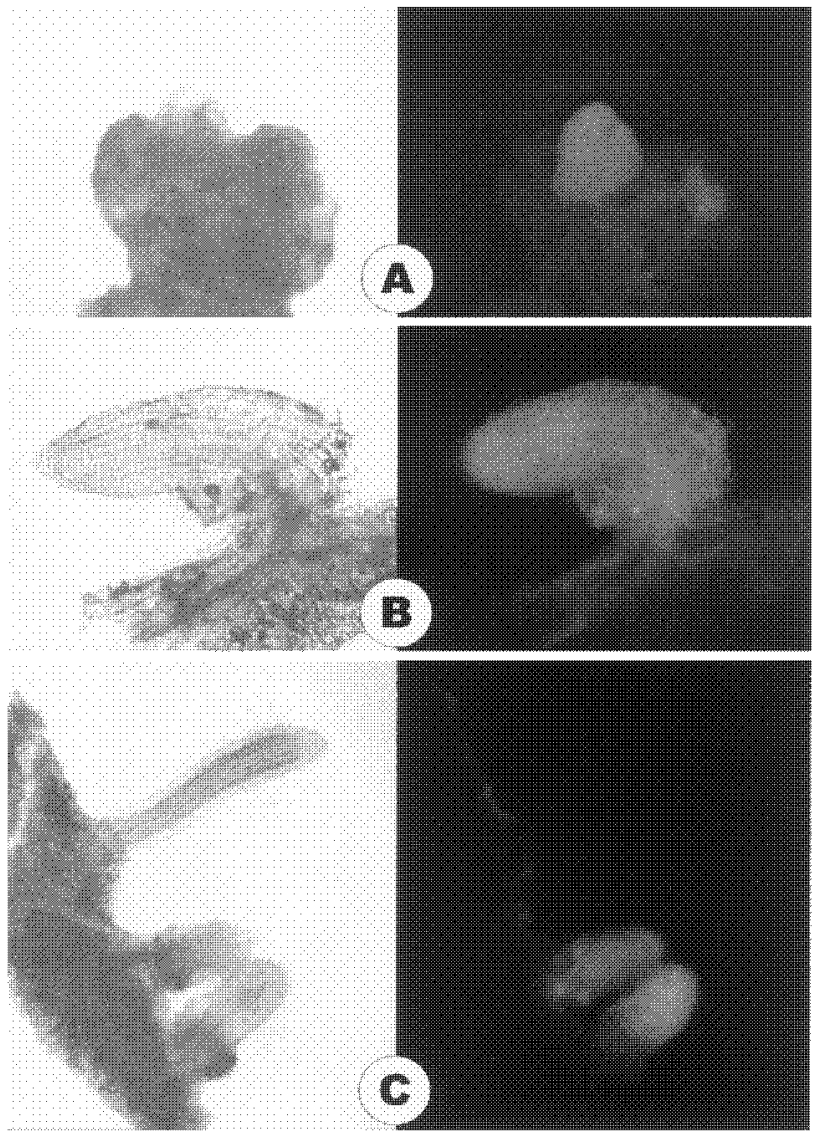

Fig. 1 Light (left) and fluorescent micrographs (right) of GFP-expressing hairy roots from calli produced by tomato leaf segments inoculated with A. rhizogenes MAFF07-20001 carrying binary vectors $\mathrm{pRi}$ and $\mathrm{pBI} 121 / \mathrm{sGFP}$. Photographs were taken at the same sites of inoculated leaves (cv. 'Ponderosa') under light and fluorescent fields of microscope. (A) and (B), GFP-fluorescing roots developed from abundantly proliferated calli (10 days after inoculation) and slightly proliferated calli (13 days after inoculation), respectively; (C), GFP-fluorescing hairy roots and non-fluorescing adventitious root developed from different calli induced in the same leaf segment (18 days after inoculation). tomato used in the present study are listed in Table 1. Seeds were germinated on a filter paper in a moistened petri dish, then hydroponically cultured for one month by the method reported previously (Nonomura et al., 2001). The leaflets of the fifthleaves were detached from the one-month-old seedlings and inoculated with $A$. rhizogenes. Inoculation was carried out according to the previous method (Toyoda et al., 1991) with a slight modification. Namely, detached leaves were rinsed with sterile water, cut horizontally into two segments and dipped in an inoculum for 5 to $10 \mathrm{~min}$. Inoculated leaves were stuck vertically into agar-solidified, sucrose-- free MS medium (Murashige and Skoog, $1962)$ and incubated at $26^{\circ} \mathrm{C}$ under continuous illumination of fluorescent lamp (3,000 lux). Induction of calli and hairy roots in inoculated leaf segments were recorded on a daily base for three weeks. GFP fluorescence in adventitious roots was observed under an Olympus fluorescence microscope BX-60 (IB excitation with BP460-490 excitation filter and BA510IF absorption filter).

Prior inoculation of all tested tomato cultivars, we attempted to observe morphological changes in inoculated leaf segments of 'Ponderosa' that used routinely as a standard cultivar in our laboratory. First, calli were induced at the edge of excised leaf segments 10 to 12 days, and then the differentiated primordial root tips with green fluorescence 13 to 15 days after inoculation (Fig. 1A). These fluorescing primordial roots vigorously elongated on hormone-free medium (Fig. 1B). As shown in Fig. 1C, the green-fluorescing roots were distinguishable from non-fluorescent adventitious roots under blue light irradiation. In addition, other tomato cultivars also produced hairy roots in the same manner shown in Ponderosa, although the efficiency of hairy root induction varied among them. Thus, indicating that callus induction and subsequent development of hairy roots in tomato cultivars are recognizable in response to the inoculation with the present isolate.

To confirm successful integration of both $\mathrm{sGFP}$ and rol $\mathrm{C}$ genes into the chromosome of fluorescing roots, chromosomal DNA was extracted from bacteria-free fluorescing roots by $C$ TAB method (Rogers et al., 1985) and used for PCR. The fluorescing roots were subcultured for three months at a 10 - day interval and used for the experiment. Nonfluorescing roots ( 3 to $4 \mathrm{~cm}$ long) were detached from leaf segments, surface-sterilized and homogenized for DNA extraction. PCR was conducted according to the previous method (Matsuda et al, 2001a), with two sets of PCR primers (PGs/PGa, $5^{\prime}$ -ATGGTGAGCAAGGGCGAGGAG-3'/5' - TTA- 
Table 1 Evaluation of tomato cultivars for production of GFP - expressing hairy roots in leaf segments inoculated with Agrobacterium rhizogenes ${ }^{1)}$

\begin{tabular}{|c|c|c|c|c|c|}
\hline \multirow{2}{*}{ Cultivars } & \multirow{2}{*}{ Producers $^{2)}$} & \multirow{2}{*}{$\begin{array}{l}\text { Number of leaf } \\
\text { segments used for } \\
\text { inoculation }(A)\end{array}$} & \multicolumn{2}{|c|}{ Total number of roots with } & \multirow{2}{*}{$\begin{array}{l}\text { Averaged number of } \\
\text { GFP-fluorescing roots } \\
\text { per segment }(\mathrm{B} / \mathrm{A})\end{array}$} \\
\hline & & & no fluorescence & green fluorescence (B) & \\
\hline Kiomaru & $\mathrm{MA}$ & 30 & 1 & 10 & 0.33 \\
\hline Ojyu & TA & 160 & 39 & 35 & 0.22 \\
\hline K 29 & KU & 108 & 21 & 23 & 0.21 \\
\hline Toyomasa & SA & 30 & 3 & 6 & 0.20 \\
\hline Putit & TA & 225 & 63 & 44 & 0.20 \\
\hline Chibikko & MA & 148 & 16 & 26 & 0.18 \\
\hline House Momotaro & TA & 452 & 137 & 83 & 0.18 \\
\hline Fukuju $\mathrm{Ni}$ gou & $\mathrm{TA}$ & 151 & 14 & 25 & 0.17 \\
\hline Pepe & TA & 141 & 26 & 24 & 0.17 \\
\hline Ponderosa & TA & 274 & 45 & 45 & 0,16 \\
\hline Chika & $\mathrm{TA}$ & 170 & 49 & 28 & 0.16 \\
\hline Corona & MA & 233 & 18 & 36 & 0.15 \\
\hline $\mathrm{K}-30$ & $\mathrm{KU}$ & 241 & 21 & 33 & 0.14 \\
\hline Odoriko & SA & 288 & 34 & 40 & 0.14 \\
\hline $\mathrm{K}-54$ & KU & 93 & 20 & 12 & 0.13 \\
\hline Kyouryokuminori & MA & 227 & 73 & 30 & 0.13 \\
\hline Yellow Pico & $\mathrm{TA}$ & 143 & 6 & 17 & 0.12 \\
\hline Twinkle Sweet & MA & 137 & 10 & 17 & 0.12 \\
\hline $\mathrm{K}-28$ & KU & 94 & 7 & 11 & 0.12 \\
\hline$K-37$ & KU & 114 & 13 & 14 & 0.12 \\
\hline Kyouryoku Beiju Ni-gou & $\mathrm{TA}$ & 169 & 22 & 21 & 0.12 \\
\hline $\mathrm{K}-50$ & KU & 100 & 17 & 12 & 0.12 \\
\hline Kyouryoku Beiju & $\mathrm{TA}$ & 212 & 42 & 25 & 0.12 \\
\hline Momotaro & $\mathrm{TA}$ & 291 & 13 & 32 & 0.11 \\
\hline$K \cdots 31$ & $\mathrm{KU}$ & 80 & 4 & 9 & 0.11 \\
\hline Hikari Fukuju & $\mathrm{MA}$ & 70 & 4 & 7 & 0.10 \\
\hline Saturn & TA & 127 & 9 & 13 & 0.10 \\
\hline Hakko & $\mathrm{MA}$ & 84 & 6 & 8 & 0.10 \\
\hline Momotaro Eight & $\mathrm{TA}$ & 174 & 19 & 18 & 0.10 \\
\hline Minicarol & AT & 96 & 12 & 10 & 0.10 \\
\hline Home Momotaro & TA & 205 & 26 & 20 & 0.10 \\
\hline Pico & TA & 60 & 8 & 6 & 0.10 \\
\hline Yubi & MA & 60 & 11 & 6 & 0.10 \\
\hline Moneymaker & $\mathrm{TE}$ & 85 & 2 & 8 & 0.09 \\
\hline $\mathrm{Coco}$ & TA & 192 & 21 & 18 & 0.09 \\
\hline Momotaro York & TA & 180 & 24. & 16 & 0.09 \\
\hline $\mathrm{K}-98$ & $\mathrm{KU}$ & 66 & 14 & 6 & 0.09 \\
\hline Momotaro T-93 & $\mathrm{TA}$ & 133 & 5 & 10 & 0.08 \\
\hline Zuiei & $\mathrm{SA}$ & 62 & 3 & 5 & 0.08 \\
\hline Hokin Fukuju & To & 223 & 21 & 17 & 0.08 \\
\hline Marryroad & SA & 135 & 14 & 11 & 0.08 \\
\hline Sekaiichi & $\mathrm{MA}$ & 113 & 8 & 8 & 0.07 \\
\hline Shubi & MA & 30 & 2 & 2 & 0.07 \\
\hline$K-97$ & $\mathrm{KU}$ & 86 & 7 & 6 & 0.07 \\
\hline$K-86$ & KU & 126 & 16 & 9 & 0.07 \\
\hline Toyofuku & $\mathrm{SA}$ & 130 & 12 & 8 & 0.06 \\
\hline Firstpower & $\mathrm{SA}$ & 66 & 3 & 3 & 0.05 \\
\hline Yellow Pear & TA & 195 & 16 & 9 & 0.05 \\
\hline Sugarlamp & $\mathrm{AT}$ & 40 & 16 & 2 & 0.05 \\
\hline Puti Eru & To & 46 & 1 & 2 & 0.04 \\
\hline K 84 & KU & 146 & 6 & 6 & 0.04 \\
\hline Red Pear & $\mathrm{TA}$ & 155 & 11 & 6 & 0.04 \\
\hline LS - 89 & $\mathrm{SA}$ & 79 & 0 & 1 & 0.01 \\
\hline$K-83$ & KU & 178 & 3 & 2 & 0,01 \\
\hline K-91 & $\mathrm{KU}$ & 160 & 0 & 0 & 0.00 \\
\hline$K-92$ & $\mathrm{KU}$ & 173 & 4 & 0 & 0.00 \\
\hline
\end{tabular}

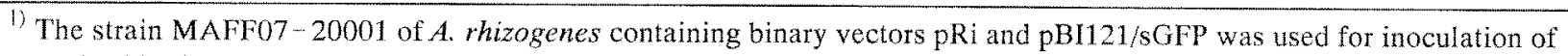
excised leaf segments of tomato cultivars. Root induction was recorded on daily basis during the entire period of incubation (for 3 weeks).

2) TA, Takii Seeds, Kyoto, Japan; MA, Marutane Seeds, Kyoto, Japan; SA, Sakata Seeds, Yokohama, Japan; TO, Tohoku Seeds, Utsunomiya, Japan; AT, Atariya Noen, Chiba, Japan; TE, Thomas Etty, Esq., United Kingdom; KU, Kinki University, Nara, Japan. K-28 to K-98, breeding lines of tomato in Kinki University. 


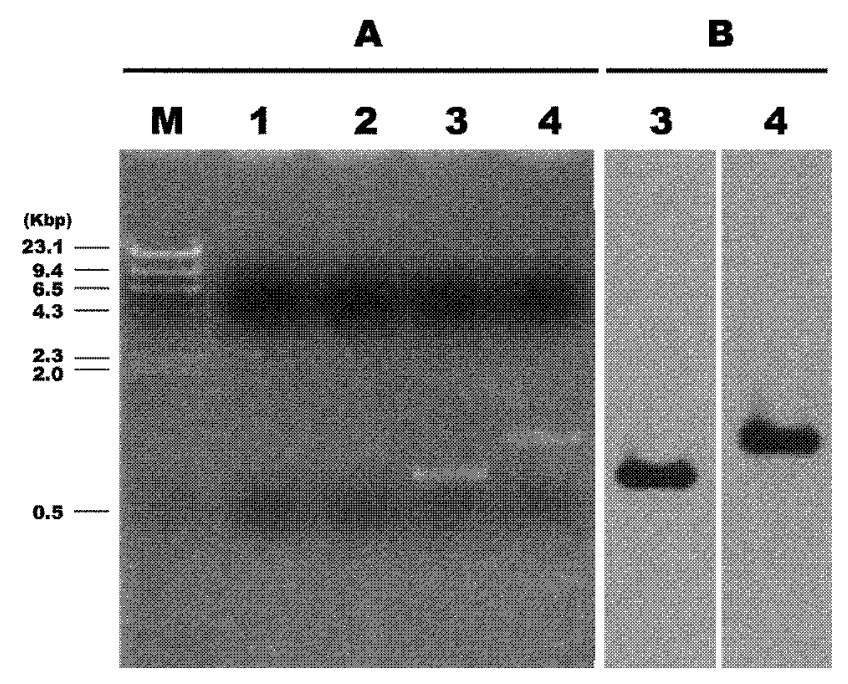

Fig. 2 Agarose-gel electrophoresis (A) and Southern hybridization (B) of $\mathrm{PCR}$-products amplified from chromosomal DNA of non-fluorescing (lanes 1 and 2) and GFP - fluorescing roots (lanes 3 and 4 ). The PCR products were hybridized with the sGFP gene (lane 3 in $B$ ) or rol C gene (lane 4) as a probe.

CTTGTACAGCTCGTCCATGCC-3'; PRs/PRa, 5' GAAGGAGTCGTGGCTAGTTAAGTGC - 3\% $5^{\prime-}$ AGCTACTGCCATCACTCCATTCCAAA - 3')

specifically amplifying the $\mathrm{SGFP}$ and rol $\mathrm{C}$ genes, respectively. The primers were constructed on the basis of their nucleotide sequences reported. PCR products were electrophoresed on $0.9 \%$ agarose gels and transferred to nylon membrane for Southern hybridization. The sGFP and rol $\mathrm{C}$ genes clipped out of the original plasmids were labeled and used as probes for hybridization. Designated DNA products were amplified from chromosomal DNA of fluorescing roots and positively hybridized with the original genes used as probe (Fig. 2). In this experiment, ten fluorescing and non-fluorescing roots were selected randomly for this assay. The result confirmed that all of fluorescing roots tested were successfully integrated with both genes, however, neither DNA amplification nor hybridization signal was detected in all non-fluorescing roots. The nonfluorescing roots that integrated only the rol $\mathrm{C}$ gene into the chromosome were not detected in this study. Thus, the present study indicates that greenfluorescing roots were produced as the result of simultaneous integration of the SGFP and rol $\mathrm{C}$ genes on the binary vectors into the host plant chromosome, and the integrated genes were stably propagated during the subculture of hairy roots.

The present method enables us to effectively examine tomato cultivars for their production of hairy roots under blue light irradiation, without conducting the isolation, subsequent culture and DNA analysis for adventitious roots formed on inoculated leaf segments. Table 1 summarized the hairy root production by commercial tomato cultivars and our breeding lines infected with $A$. rhizogenes containing the binary vectors. Although a few breeding lines (' $\mathrm{K}-91$ ' and ' $\mathrm{K}-92$ ') were resistant to the infection by MAFF07-20001, all other tomato cultivars showed susceptibility to the strain with some variation. Such a variation was often detected in susceptible tomato cultivars, when they were inoculated with bacterial (Nonomura et al., 2001) and fungal pathogens (Matsuda et al., 2001b). The different susceptibility of the cultivars to the pathogens was considered to be due to different genetic background of host plants (Agrios, 1988; Erickson et al., 1990) or pathogenicity level of the pathogens (Anderson and Moore, 1979). Actually, the different strains (MAFF07-20002, MAFF0301724, ArM-123, ArM-248) of A. rhizogenes failed to cause the hairy root production in these tomato cultivars (data not shown). In the present study, almost all tomato cultivars available in Japan were included, and eventually they could be effectively inoculated with the strain of $A$. rhizogenes to produce hairy roots. Convincingly, the present study provides basic information for transformation of tomato cultivars by the $A$. rhizogenes mediated gene delivery.

\section{Acknowledgements}

This work was supported in part by a Grant--inAid (No. 12660050) from the Ministry of Education, Culture, Sports, Science and Technology of Japan. We gratefully acknowledge Dr. T. Shiomi, National Institute for Agro-Environmental Sciences and Dr. K. Ohta, Shizuoka Citrus Experiment Station for kindly providing the strains of A. rhizogenes, and Dr. Y. Niwa, University of Shizuoka, for kindly gifting the sGFP(S65T) gene.

\section{References}

Anderson, A. R., Moore, L. W., 1979. Host specificity in the genus Agrobacterium. Phytopathology, 69: 320-323.

Agrios, G. N., 1988. Genetics of plant disease. In: Plant Pathology, pp. 116-146. Academic Press, New York.

Chiu, W-I., Niwa, Y., Zeng, W., Hirano, T., Kobayashi, H., Sheen, J., 1996. Engineered GFP as a vital reporter in plants. Curr. Biol, 6: 325-330.

Erickson, P. I., Cello, L. M., Froelich, L. W., Bahr, J. T., 1990. Rhizogenic response of tomato genotypes to Agrobacterium rhizogenes inoculation. J. Hort. Sci., 65 : 333-337.

Matsuda, Y., Toyoda, H., Ueda, A., Tamaki, S., Hosoi, Y., Ouchi, S., 1997. Establishment of photosynthetic hairy roots in cultures of melon leaves (Cucumis melo $\mathrm{L}$.). 
Environ. Control in Biol., 35: 131- 134.

Matsuda, Y., Toyoda, H., Sawabe, A., Maeda, K., Shimizu, N., Fujita, N., Fujita, T., Nonomura, T., Ouchi, S., 2000. A hairy root culture of melon produces aroma compounds. J. Agric. Food Chem, 48: 1417-1420.

Matsuda, Y., Toyoda, H., Konagaya, K., Wakita, M., Hosoi, Y., Nonomura, T., Ouchi, S., 2001a. Circulated culture system of tobacco hairy roots for rapid evaluation of viral multiplication and movement. Bull. Inst. Compr. Agr. Sci. Kinki Univ., 9: 81-88.

Matsuda, Y., Kashimoto, K., Takikawa, Y., Aikami, R., Nonomura, T., Toyoda, H., 2001b. Occurrence of new powdery mildew on greenhouse tomato cultivars. J. Gen. Plant Pathol, 67: 294-298.

Murashige, T., Skoog, F., 1962. A revised medium for rapid growth and bio assays with tobacco tissue cultures. Physiol. Plant, 15: 473-497.

Nonomura, T., Matsuda, Y., Tsuda, M., Uranaka, K., Toyoda, H., 2001. Susceptibility of commercial tomato cultivars to bacterial wilt in hydroponic system. J. Gen. Plant Pathol., 67: 224-227.

Rogers, S. O., Bendich, A. J., 1985. Extraction of DNA from milligram amounts of fresh, herbarium and mummified plant tissues. Plant Mol. Biol., 5: 69-76.

Sawabe, A., Matsuda, Y., Toyoda, H., 2002. Aroma constituent production by the use of microorganism gene and their development. Foods Food Ingre. J. Jpn, 207: 2330 (in Japanese).

Sawabe, A., Matsuda, Y., Toyoda H., Maeda, K., Nonomura, T., Shimizu, N., Fujita, N., Ouchi, S., 2003. Constituents of volatile oil from melon hairy roots produced by the infection with Agrobacterium rhizogenes. J. Oleo Sci., 52: 171- 174.

Tanaka, N., Takao, M., Matsumoto, T., Machida, Y., 1993. Transformation of Agrobacterium rhizogenes strain MAFF03-01724 by electroporation. Ann. Phytopath. Soc. Jpn., 59: 587-593 (in Japanese).

Toyoda, H., Hosoi, Y., Yamamoto, A., Nishiguchi, T., Maeda, K., Takebayashi, T., Shiomi, T., Ouchi, S., 1991. Transformation of melon (Cucumis melo L.) with Agrobacterium rhizogenes. Plant Tissue Cult. Lett., 8: 21- 27.

Toyoda, H., Kami, C., Sumitani, K., Suo, J. Z., Hosoi, Y., Ouchi, S., 1993. Transformation of Japanese cultivars of strawberry with Agrobacterium rhizogenes. Plant Tissue Cult. Lett., 10:92-94 (in Japanese). 